\title{
Jasmine 85 from Seven Rice Seed Production Sources in Ghana Are Genetically Different
}

\author{
O. T. Akintayo ${ }^{1}$, B. K. Maalekuu ${ }^{1} \&$ J. K. Saajah ${ }^{2}$ \\ ${ }^{1}$ Kwame Nkrumah University of Science and Technology, Kumasi, Ghana \\ ${ }^{2}$ Ghana Cocoa Board/Newmont Mining Cooperation, Ghana \\ Correspondence: B. K. Maalekuu, Kwame Nkrumah University of Science and Technology, Kumasi, Ghana. \\ E-mail: kbmaalekuu.agric@knust.edu.gh
}

Received: December 14, 2014 Accepted: February 1, $2015 \quad$ Online Published: March 15, 2015

doi:10.5539/jas.v7n4p152 URL: http://dx.doi.org/10.5539/jas.v7n4p152

\begin{abstract}
Jasmine 85 is the most popular and widely cultivated rice variety in Ghana. Samples of Jasmine 85 were collected from seven seed sources with a reference sample obtained from Africa Rice Center, Senegal. Morphological evaluation involved qualitative and quantitative data. Jasmine 85 from all sources were similar in terms of aroma, anthocyanin coloration, leaf pubescence, and ligule shape. The sources showed significant differences to pericarp colour, days to $50 \%$ heading, plant height, seed length and seed width.

Physico-chemical analyses showed grain size and shape, grain chalkiness; cooking time, head rice yield, gelatinisation temperature, amylose content and viscosity properties differed significantly among the sources whilst grain hardness was not significantly different.

Molecular characterisation using 15 SSR markers showed that although closely related, the sources differed significantly. None of the sources in Ghana was genetically identical to the reference sample. Seeds from different sources should not be mixed for sale or production, and these varieties should be treated separately in future evaluations.
\end{abstract}

Keywords: chalkiness, physic-chemical, gelatinisation temperature, anthocyanin coloration, viscosity, amylose content, significant, clustering

\section{Introduction}

The rice import bill of Ghana is about US\$300 million accounting for 70\% of local demand (MoFA, 2009). As rice imports surge ahead of production in Ghana, increasing rice production and yields has become a priority. Annual per capita consumption of rice in Ghana grew from $17.5 \mathrm{~kg}$ during 1999-2001 to $24 \mathrm{~kg}$ during 2010-2011. As only 5 per cent of global production is traded, local production would also protect consumers from price shocks in the world rice market (World Bank, 2013). While substantial investments in national rice production have been made, local production is still not able to keep up with growing demand for rice in Ghana. Although local production of milled rice recently has grown by 10.5 per cent annually, from 242,000 metric tons (MT) in 2004 to $481,000 \mathrm{MT}$ in 2012, most of this growth in production has come from area expansion (7.5 per cent), with the remaining 3.0 per cent coming from productivity improvements. Despite these efforts, Ghana imported 640,000 MT of rice in 2013 (IFPRI, 2014)

Ghana rice market places premium on long slender intermediate amylose aromatic grains. Thus Jasmine 85, market quality rice variety developed by the International Rice Research Institute (IRRI) from the cross IR262-43-8-11/KHAO DAWK MALI 4-2-105 (Marco et al., 1997) and released 1998 in Ghana as Gbewaa rice by CSIR-Savannah Agricultural Research Institute (CSIR-SARI) (Diako et al., 2011) is grown all over the country. Dartey (unpublished) found that Jasmine 85 grown by Prairie Volta Co. Ltd. was morphologically different from that grown by CSIR-Crops Research Institute (CSIR-CRI), and both were different from that obtained from CSIR-SARI. This study sought to use morphology, biochemical and molecular tools to determine differences among Jasmine 85 from different sources so as to improve seed quality.

\section{Materials and Methods}

Two samples Jasmine 85 were collected from SARI, Tamale (denoted GBEWAA and SARI) and from CSIR-CRI in Nobewam (denoted DARTEY) and Kumasi (denoted CRI). Samples were also collected from Kpong 
Irrigation Project, Asutsuare (denoted KIP), Prairie Volta Co Ltd, Aveyime (denoted PV), Tono Irrigation Project, Tono (denoted TONO) with the reference sample from AfricaRice, Senegal (denoted ARI).

The varieties were evaluated under irrigation in a randomized complete block design with four replicates in Nobewam (North 6 $6^{\circ} 37^{\prime} 6.2^{\prime \prime}$, West $1^{\circ} 17^{\prime} 0.4^{\prime \prime}, 200 \mathrm{~m}$ above the sea level) on $4 \mathrm{~m}^{2}$ plots.

After harvest, visibly off-types were disregarded and seed from true to type plants were used to carry out the laboratory analyses. Complete randomized design of ... replicates was used for analyses of the physico-chemical and molecular properties.

To detect aroma, young leaf samples were put in an eppendorf tube containing alcohol ( $90 \%$ ethanol), closed for 24 hours and smelt by a panel of 4 persons.

All other morphological data were taken following the Standard Evaluation System for rice.

\subsection{Moisture Content}

Moisture content of samples were taken on two replicate samples of 50grains using PQ-510 Single Kernel Moisture Meter (Kett, Japan).

\subsection{Milling Recoveries}

Rice samples were dehusked in a THU-34A Satake Testing Rice Husker (Satake, Japan). The brown rice obtained was polished in a Rice pal 32 (Yamamoto Co., Japan) rice polisher. Milled rice was separated into whole and broken grains using a Test rice grader. The milling recoveries were then estimated using the following equations:

$$
\begin{aligned}
& \text { Brown rice yield }(\%)=100 \times \frac{\text { weight of dehusked rice }}{\text { weight of paddy }} \\
& \text { Total milling yield }(\%)=100 \times \frac{\text { weight of polished rice }}{\text { weight of paddy }} \\
& \text { Head rice yield }(\%)=100 \times \frac{\text { weight of whole grains }}{\text { weight of paddy }}
\end{aligned}
$$

\subsection{Raw Grain Hardness}

Grain hardness was measured using a grain hardness tester (Fujihara Seisakusho LDT, Japan). Ten grains were used for each sample. The handle of the equipment was initially turned anti-clockwise to make room to place a grain on the sample table. Consequently, the handle was turned clockwise until a cracking sound was heard. At this time, the black pointer returns to the zero point and the red pointer remained. The reading of the red pointer $(\mathrm{kg})$ indicated the hardness of the grain.

\subsection{Grain Dimension and Chalkiness}

Grain dimensions and chalkiness were estimated using the S21 Rice Statistic Analyzer, (LKL Technologia, Brazil). The equipment is run with a Classficador S21 version 4.05 software. The S21 was calibrated using a reference sample supplied by the manufacturer. The fluorescent light on the S21 was turned on and approximately $50 \mathrm{~g}$ of whole grains weighed and emptied into its sample receiver. The "long white" classification set up was opened in the capture mode on the software. The equipment was then switched on to vibrate and cause the release of individual grains from the receiver to slide on a blue tile background and pass beneath the attached camera that captured images of the grains. When all the grains had exited the receiver the image capturing mode was stopped. The grain dimensions were determined by processing the captured images and applying the "advanced filter-length distribution" on the software. The grain length and width were then recorded and the length/width ratio calculated. To determine chalkiness, the "basic filter - chalky distribution" was applied. The $\%$ total chalky area for the samples were recorded and reported as the percentage chalkiness of the samples.

\subsection{Alkali Spreading Value (ASV)}

ASV was determined using the method developed by Little et al. (1958) which involves visual observation of the degree of dispersion of grains of the milled rice after their immersion in $1.7 \%$ potassium hydroxide solution $(\mathrm{KOH})$. Approximately $10 \mathrm{ml}$ of $1.7 \% \mathrm{KOH}$ solution was poured on 6 rice grains placed in a transparent petri dish and incubated at room temperature for 23 hours after which the samples were observed and visual scores (Jennings et al., 1979) assigned. Based on the alkali spreading value, the gelatinization temperature (GT) of 
samples was indirectly determined.

\subsection{Pasting Properties}

The pasting properties of rice flour samples were measured using a Rapid Visco Analyzer (RVA) model - Super 4 (Newport Scientific, Warriewood, Australia) and Thermocline for Windows (TCW3) software. The general pasting method 162 (ICC, 2004) for flour samples was used. Rice flour (3 g sample) was weighed directly into the RVA canister, $25 \mathrm{ml}$ of distilled water was added and mixed with the rice flour. The canister and its content were then placed in the RVA and run using the following RVA test profile:

- $\quad$ Rotating paddle speed - $160 \mathrm{rpm}$,

- Heating the rice-water mixture to $95^{\circ} \mathrm{C}$ at a rate of $12{ }^{\circ} \mathrm{C} / \mathrm{min}$ (i.e. in $3.75 \mathrm{~min}$ ),

- Holding at $95^{\circ} \mathrm{C}$ for $2.5 \mathrm{~min}$,

- Cooling to $50^{\circ} \mathrm{C}$ at a rate of $12^{\circ} \mathrm{C} / \mathrm{min}$ (i.e. in $3.75 \mathrm{~min}$ ), and

- Holding at $50^{\circ} \mathrm{C}$ for $2.5 \mathrm{~min}$.

\subsection{Cooking Time}

Cooking time was determined using the method described by Fofana et al. (2011). Five grams of milled rice of each sample were weighed in duplicate and poured into $135 \mathrm{ml}$ of vigorously boiling distilled water in a $400 \mathrm{ml}$ beaker and covered with a watch glass. After 10 minutes of further boiling, 10 grains were taken out every minute with a perforated ladle. The grains were pressed between two petri dishes and were considered cooked when at least 9 out of the 10 grains no longer had opaque centers. The time it took for this to happen was then recorded as the cooking time for the sample.

\subsection{Amylose Content}

Amylose content is measured using the standard iodine colorimetric method ISO 6647-2-2011. Ethanol (1 mL, $95 \%)$ and $1 \mathrm{M}$ sodium hydroxide $(9 \mathrm{~mL})$ is added to rice flour $(100 \mathrm{mg})$ and this is heated in a boiling water bath until gelatinization of the starch occurred. After cooling, $1 \mathrm{M}$ acetic acid $(1 \mathrm{~mL})$ and iodine solution $(2 \mathrm{~mL})$ are added and the volume is made up to $100 \mathrm{~mL}$ with Millipore water. The iodine solution is prepared by dissolving $0.2 \mathrm{~g}$ iodine and $2.0 \mathrm{~g}$ potassium iodide in $100 \mathrm{~mL}$ Millipore water. Absorbance of the solution is measured using an Auto Analyzer 3 (Seal Analytical, Germany) at $600 \mathrm{~nm}$. Amylose content is quantified from a standard curve generated from absorbance values of 4 well-known standard rice varieties (IR65, IR24, IR64 and IR8).

Molecular tests were done using fresh leaves from 3 weeks old rice seedlings. The CTAB method was used for DNA extraction. The DNA was suspended in $50 \mu \mathrm{l} 1 \mathrm{X}$ TE buffer and centrifuged at high speed for $30 \mathrm{sec}$ to remove all insolubles. During that time $1.0 \%$ of agarose gel was prepared with $(3 \mu \mathrm{l}) 0.003 \%$ Ethidium bromide. $5 \mu \mathrm{l}$ of the sample was taken using pipette, and added to $1 \mu \mathrm{l}$ loading buffer. The sample was loaded in the wells on gel submerged in 1X TAE buffer and the sample was run at (90 to 120) volts for 45 minutes. The computer connected to the machine recorded the data and pictured the gel.Fifteen SSR rice primers (RM252, RM511, RM316, RM8236, RM224, RM19, RM452, RM144, RM514, RM105, RM277, RM25, RM178, RM11\& RM55) were used.

\section{Results and Discussion}

\subsection{Qualitative Traits}

Data for qualitative traits considered for the morphological evaluation is presented in Table 1. 
Table 1. Aroma, anthocyanin coloration, leaf pubescence, pericarp colour and ligule shape of the various seed sources

\begin{tabular}{llllll}
\hline Treatment & Aroma & Anthocyanin coloration & Leaf pubescence & Pericarp colour & Ligule Shape \\
\hline ARI & Lightly scented & Absent & Pubescent & Light brown & 2-cleft \\
CRI & Lightly scented & Absent & Pubescent & Light brown & 2-cleft \\
DARTEY & Lightly scented & Absent & Pubescent & Light brown & 2-cleft \\
GBEWAA & Lightly scented & Absent & Pubescent & Light brown & 2-cleft \\
KIP & Lightly scented & Absent & Pubescent & Light brown & 2-cleft \\
PV & Lightly scented & Absent & Pubescent & Light brown & 2-cleft \\
SARI & Lightly scented & Absent & Pubescent & Red & 2-cleft \\
TONO & Lightly scented & Absent & Pubescent & Light brown & 2-cleft \\
\hline
\end{tabular}

With the exception of pericarp colour where SARI had red whilst the others had light brown, no difference was observed with respect to the qualitative data. According to IRRI (1998), Jasmine 85 has pubescent leaves, no anthocyanin colouration, light brown pericarp and is aromatic. With respect to the above description, seeds from SARI do not match a true Jasmine 85 variety.

\subsection{Quantitative Data}

Data for the quantitative traits are presented in Table 2.

Table 2. Means of 50\% heading (days); plant height (m); number of tiller; seed length (mm) and seed width (mm) for the various seed sources

\begin{tabular}{lllllll}
\hline Treatment & $\begin{array}{l}\text { Means of 50\% } \\
\text { heading (days) }\end{array}$ & $\begin{array}{l}\text { Plant } \\
(\mathbf{m})\end{array}$ & $\begin{array}{l}\text { height } \\
\text { tiller }\end{array}$ & $\begin{array}{l}\text { Seed length } \\
(\mathbf{m m})\end{array}$ & $\begin{array}{l}\text { Seed } \\
(\mathbf{m m})\end{array}$ & width \\
\hline ARI & $69.25^{\mathrm{c}}$ & $95.1^{\mathrm{e}}$ & $7.62^{\mathrm{cd}}$ & $10.57^{\mathrm{a}}$ & $2.25^{\mathrm{a}}$ \\
CRI & $84^{\mathrm{a}}$ & $111.4^{\mathrm{abc}}$ & $10.75^{\mathrm{b}}$ & $10.53^{\mathrm{a}}$ & $2.22^{\mathrm{a}}$ \\
DARTEY & $85^{\mathrm{a}}$ & $113.7^{\mathrm{ab}}$ & $6.84^{\mathrm{cd}}$ & $10.32^{\mathrm{b}}$ & $2.213^{\mathrm{ab}}$ \\
GBEWAA & $74.25^{\mathrm{b}}$ & $106.9^{\mathrm{cd}}$ & $8.40^{\mathrm{bcd}}$ & $9.56^{\mathrm{f}}$ & $2.213^{\mathrm{ab}}$ \\
KIP & $71.50^{\mathrm{bc}}$ & $97.1^{\mathrm{e}}$ & $7.23^{\mathrm{cd}}$ & $10.24^{\mathrm{bc}}$ & $2.28^{\mathrm{a}}$ \\
PV & $83.50^{\mathrm{a}}$ & $115.7^{\mathrm{a}}$ & $16.34^{\mathrm{a}}$ & $10.12^{\mathrm{cd}}$ & $2.05^{\mathrm{c}}$ \\
SARI & $84.25^{\mathrm{a}}$ & $109^{\mathrm{bcd}}$ & $9.18^{\mathrm{bc}}$ & $9.94^{\mathrm{de}}$ & $2.123^{\mathrm{bc}}$ \\
TONO & $71.50^{\mathrm{bc}}$ & $105.2^{\mathrm{d}}$ & $6.28^{\mathrm{d}}$ & $9.86^{\mathrm{e}}$ & $2.205^{\mathrm{ab}}$ \\
\hline LSD & 3.02 & 5.65 & 2.68 & 0.18 & 0.094 \\
CV (\%) & 2.6 & 3.6 & 20.1 & 1.3 & 2.9 \\
\hline
\end{tabular}

Note. Means with same alphabet within column are not significantly different at $5 \%$.

The average heading days ranged from 85 days for DARTEY to 69 days for ARI. Significant differences were observed in all the sources implying that the materials differ in terms of maturity days. Significant differences were also observed in number of tillers, seed length and seed weight. Although the study recorded a plant height range of $115.7 \mathrm{~cm}$ to $95 \mathrm{~cm}$ which is in agreement with IRRI's (1998) report for Jasmine 85, significant variations recorded for other traits undermine the genetic purity of this popular variety in Ghana. Ideally, a single variety from different sources should not vary significantly in these traits.

\subsection{Physico-Chemical Analysis}

The physico-chemical variables measured on the grain helped reveal differences in the Jasmine 85 from the various sources. The analysis of variance (ANOVA) showed significant difference for all parameters measured except for Grain hardness (Table 3). 
Table 3. Means of Grain length $(\mathrm{mm})$, grain width $(\mathrm{mm})$, grain length to the width ratio, grain size, grain shape, total chalky area $(\%)$, and grain hardness $(\mathrm{kg})$ of Jasmine 85 from various sources

\begin{tabular}{llllllll}
\hline Treatment & $\begin{array}{l}\text { Length } \\
(\mathbf{m m})\end{array}$ & $\begin{array}{l}\text { Width } \\
\mathbf{( m m})\end{array}$ & $\mathbf{L} / \mathbf{W}$ & Size & Shape & $\begin{array}{l}\text { Total chalky area } \\
\mathbf{( \% )}\end{array}$ & $\begin{array}{l}\text { Grain hardness } \\
\mathbf{( k g )}\end{array}$ \\
\hline ARI & $6.61^{\mathrm{a}}$ & $2.208^{\mathrm{ab}}$ & 3.0 & Long & Medium & $9.24^{\mathrm{e}}$ & 9.02 \\
CRI & $6.505^{\mathrm{ab}}$ & $2.198^{\mathrm{b}}$ & 3.0 & Medium & Medium & $15.04^{\mathrm{b}}$ & 8.13 \\
DARTEY & $6.38^{\mathrm{bc}}$ & $2.035^{\mathrm{f}}$ & 3.1 & Medium & Slender & $12.41^{\mathrm{c}}$ & 7.83 \\
GBEWAA & $6.308^{\mathrm{c}}$ & $2.127^{\mathrm{d}}$ & 3.0 & Medium & Medium & $20.80^{\mathrm{a}}$ & 8.89 \\
KIP & $6.367^{\mathrm{bc}}$ & $2.225^{\mathrm{a}}$ & 2.9 & Medium & Medium & $10.99^{\mathrm{d}}$ & 8.09 \\
PV & $6.365^{\mathrm{bc}}$ & $2.035^{\mathrm{f}}$ & 3.1 & Medium & Slender & $13.16^{\mathrm{c}}$ & 8.25 \\
SARI & $6.078^{\mathrm{d}}$ & $2.083^{\mathrm{e}}$ & 2.9 & Medium & Medium & $7.34^{\mathrm{f}}$ & 8.96 \\
TONO & $6.44^{\mathrm{bc}}$ & $2.155^{\mathrm{c}}$ & 3.0 & Medium & Medium & $14.30^{\mathrm{b}}$ & 8.43 \\
\hline LSD & 0.156 & 0.021 & - & - & - & 1.019 & 1.22 \\
CV $(\%)$ & 1.7 & 0.7 & - & - & - & 5.4 & 10
\end{tabular}

Note. Means with same alphabet within columns are not significantly different at 5\%.

The alkaline spreading value gave three classes of gelatinisation temperature: low $\left(<70{ }^{\circ} \mathrm{C}\right)$, intermediate $\left(70-74^{\circ} \mathrm{C}\right)$ and high $\left(74.5-80{ }^{\circ} \mathrm{C}\right)$ (Table 4). The amylose content was also significantly different for all seed sources except between PV and DARTEY and ARI and DARTEY. GBEWAA recorded the highest amylose content of $20.64 \%$ while SARI recorded $10.63 \%$ as the lowest. IRRI (1998) report indicates that Jasmine 85 has low gelatinisation temperature (65 to 68\%) and low amylose. Diako et al. (2011) also reported in their study that Jasmine 85 has amylose content of $20.2 \%$.

Table 4. Alkaline spreading value, gelatinisation temperature $\left({ }^{\circ} \mathrm{C}\right)$ and its classification $\left({ }^{\circ} \mathrm{C}\right)$, and means of the amylose content $(\%)$ for the various seed sources

\begin{tabular}{lllll}
\hline Treatment & $\begin{array}{l}\text { Alkaline spreading } \\
\text { value }\end{array}$ & $\begin{array}{l}\text { Gelatinisation temperature } \\
\left({ }^{\circ} \mathbf{C}\right)\end{array}$ & $\begin{array}{l}\text { Temperature } \\
\text { classification }\end{array}$ & $\begin{array}{l}\text { Amylose content } \\
(\%)\end{array}$ \\
\hline PV & 7 & $<70^{\circ} \mathrm{C}$ & Low & $14.51^{\mathrm{e}}$ \\
GBEWAA & 5 & $70-74^{\circ} \mathrm{C}$ & Intermediate & $20.64^{\mathrm{a}}$ \\
ARI & 7 & $<70^{\circ} \mathrm{C}$ & Low & $14.85^{\mathrm{d}}$ \\
TONO & 6 & $<70^{\circ} \mathrm{C}$ & Low & $18.07^{\mathrm{b}}$ \\
DARTEY & 7 & $<70^{\circ} \mathrm{C}$ & Low & $14.65^{\mathrm{de}}$ \\
SARI & 2 & $74.5-80^{\circ} \mathrm{C}$ & High & $10.63^{\mathrm{g}}$ \\
KIP & 7 & $<70^{\circ} \mathrm{C}$ & Low & $14.13^{\mathrm{f}}$ \\
CRI & 7 & $<70^{\circ} \mathrm{C}$ & Low & $15.79^{\mathrm{c}}$ \\
\hline LSD & - & - & - & 0.31 \\
$\mathrm{CV}(\%)$ & - & - & - & 1.4 \\
\hline
\end{tabular}

Note. The means with the same alphabet within columns are not significantly different at 5\%.

The peak obtained from the viscosity test (Figure 1) gave information on treatment viscosity. The Treatment with the highest peak viscosity was SARI $(3537 \mathrm{cP})$. GBEWAA $(2791 \mathrm{cP})$ had the lowest peak viscosity.Pasting properties is influenced by amylose content (Tester \& Morrison, 1990); the higher the amylose content the less expansion potential and the lower the gel strength for the same starch concentration (Li \& Yeh, 2001; Singh et al., 2003). The lower the amylose content the starch granules swell much more, and hence a thicker paste is produced (Diako et al., 2011). The viscosity graph gave significant difference among the sources especially with the peak and the final viscosities. SARI had the highest peak viscosity which can be explained by its lowest 
amylose content; GBEWAA on the other hand expressed the lowest peak viscosity and high amylose content.

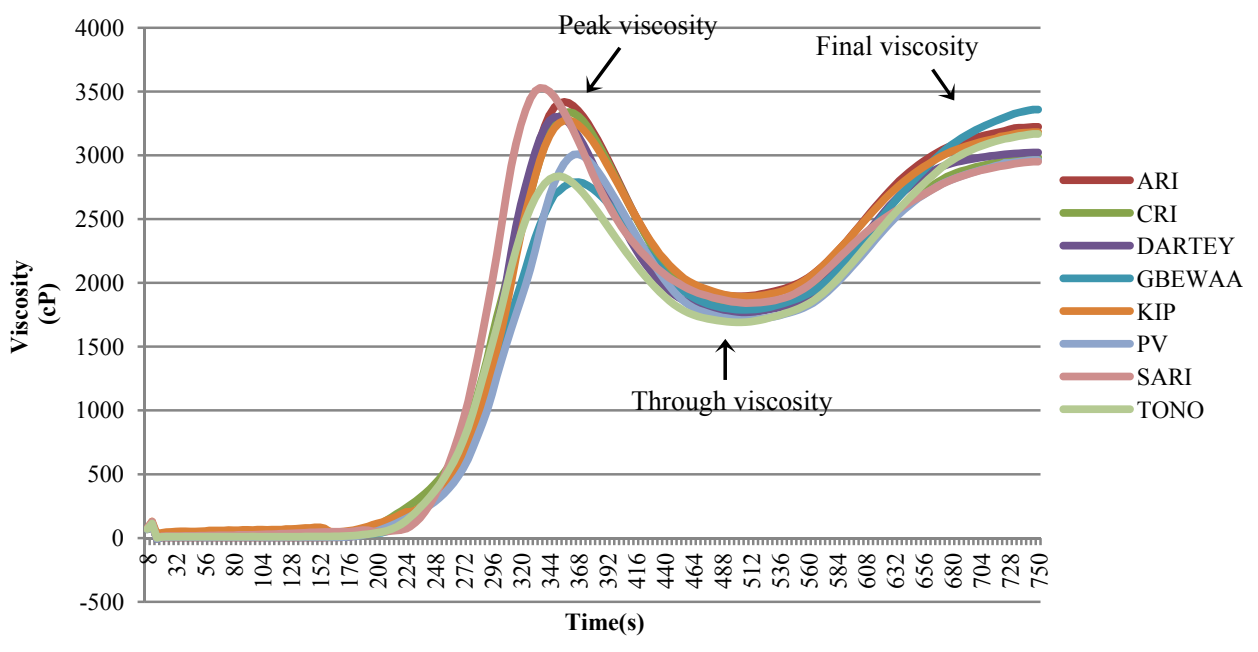

Figure 1. Means of the Viscosity properties of the various sources plotted against time (Centipoise)

Figure 2 represents the means of the cooking times; it varies from 23 minutes to 15.75 minutes respectively for GBEWAA and for PV. The source which has the shortest cooking time is PV and the source which has the longest cooking time is GBEWAA. The significant difference among treatments implies that mixing grains from two or more of the different sources for boiling would result in inconsistent texture of the meal. The physical appearance of the milled rice is also important in terms of consumer preference because most consumers are selective in what they eat so a mixture of different varieties would not be palatable to most consumers.

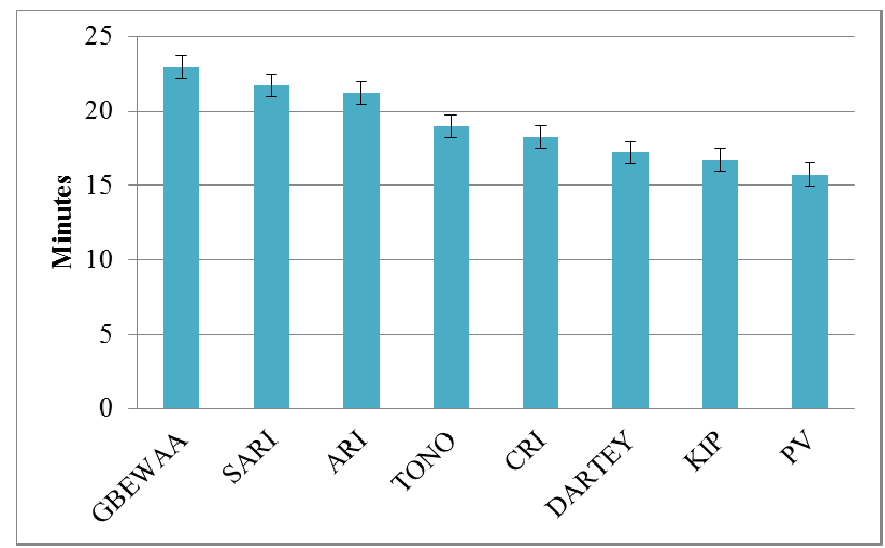

Figure 2. Means of the cooking time of the various sources

Note. LSD (1.53) is used as standard error bar to show the differences between treatments at $5 \%$.

\subsection{Source Clustering}

To categorize the seeds from the eight sources, clustering analysis was performed with morphological and grain quality characteristics. The cluster is presented in Figure 3. The hierarchical tree can be cut into 4 groups. The first group comprised CRI, DARTEY, ARI and KIP; GBEWAA and TONO formed the second group; the remaining two classes were SARI and PV in that order. For the study, ARI obtained from Africa Rice Centre in Senegal with IRRI as its original source, was used as the check. Based on the clustering, CRI, KIP and DARTEY resembles ARI and might be the true Jasmine 85 . 


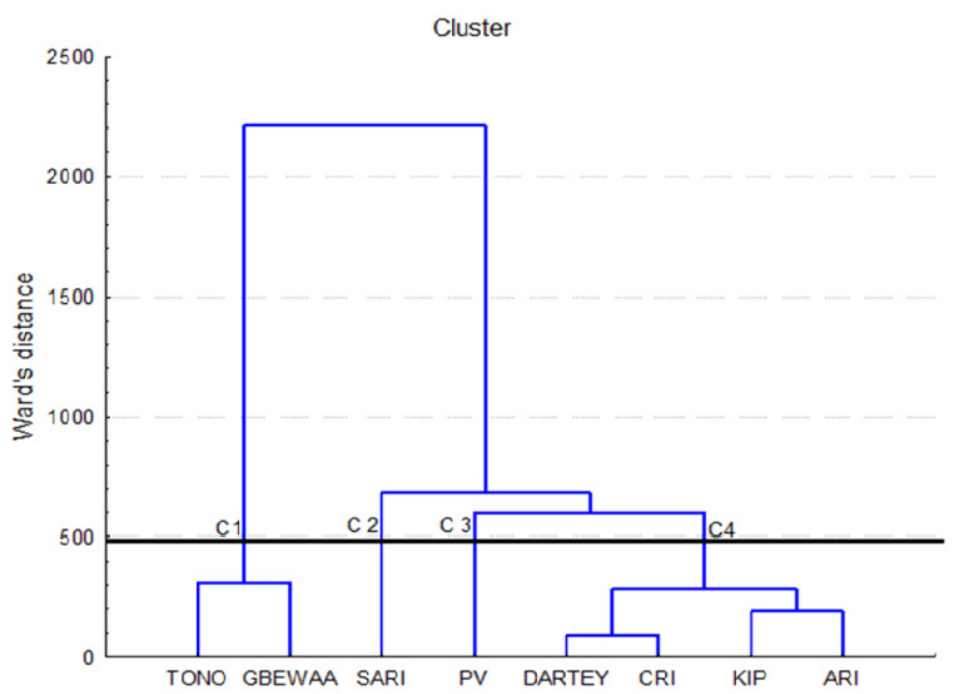

Figure 3. Cluster of the various sources using field and physico-chemical data

\subsection{Molecular Analysis}

The molecular analysis revealed GBEWAA as the most distant relative to the other seed sources with genetic distance of $0.3 \mathrm{cM}$ between (GBEWAA and CRI). The least genetic distance $(0.03 \mathrm{cM})$ was recorded between ARI and TONO; this means that ARI and TONO are closely related genetically than the other sources. The average distance between the various seed sources was $0.16 \mathrm{cM}$.The results of the similarity and dissimilarity between sources is presented in Table 5 .

Table 5. Dissimilarity between and within sources (centimogan: $\mathrm{cM}$ )

\begin{tabular}{llllllll}
\hline & ARI & DARTEY & CRI & SARI & TONO & PV & GBEWAA \\
\hline DARTEY & 0.17 & & & & & & \\
CRI & 0.13 & 0.17 & & & & & \\
SARI & 0.17 & $6.67 \mathrm{E}-02$ & 0.17 & & & & \\
TONO & $3.33 \mathrm{E}-02$ & 0.13 & 0.1 & 0.13 & & & \\
PV & 0.1 & $6.67 \mathrm{E}-02$ & 0.17 & 0.13 & $6.67 \mathrm{E}-02$ & & \\
GBEWAA & 0.23 & 0.267 & 0.3 & 0.2 & 0.2 & 0.2 & \\
KIP & 0.1 & 0.13 & 0.17 & $6.67 \mathrm{E}-02$ & $6.67 \mathrm{E}-02$ & $6.67 \mathrm{E}-02$ & 0.13 \\
\hline
\end{tabular}

Compared to the morpho-physico chemical cluster (Figure 3), the molecular clustering showed three classes of cluster (Figure 4). Cluster 1 composed of PV; DARTEY; and SARI, within this cluster PV is distinguished from the two other sources. Cluster 2 composed CRI, ARI, and TONO. Cluster 3 also composed of KIP and GBEWAA, GBEWAA also is distinguished from KIP in this cluster. 


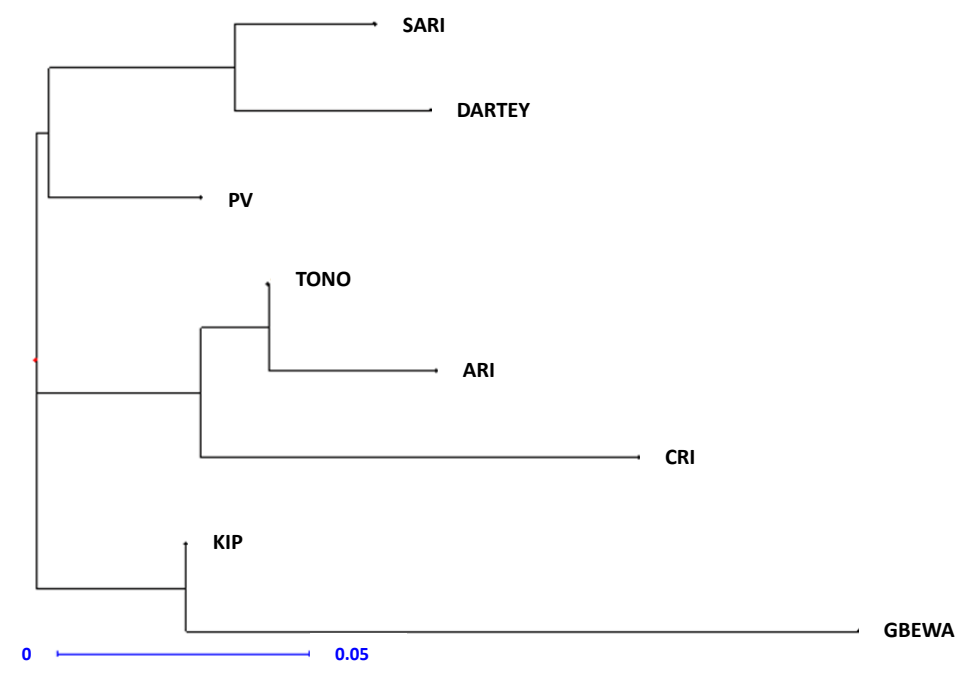

Figure 4. Molecular cluster of the sources

\section{Conclusion}

Significant genetic differences were observed at the morphological, physico-chemical and molecular levels. The seeds from the various sources are therefore genetically different and should not be mixed for production or sale.

\section{Acknowledgements}

The contributions of the various authors (O. T. Akintayo, P. K. A. Dartey, B. K. Maalekuu, J. Manful, M. Sow, M. Ndjiondjop, S. Graham-Acquaah, S. O. Abebrese, and J. K. Saajah) have been duly acknowledged for their respective roles in the completion of this work. Special thanks also go to God Almighty, for granting the needed health, understanding and guidance for towards the completion of the work. Other staff of Kwame Nkrumah University of Science and Technology, Kumasi, Ghana; Africa Rice Center, Suakoko, Liberia/CSIR-Crops Research Institute, Kumasi, Africa Rice Center, Cotonou, Benin, CSIR-Savannah Agricultural Research Institute, Tamale, Ghana and Ghana Cocoa Board/Newmont Mining Cooperation-Ghana who in diverse ways contributed to the completing of this work are all duly acknowledged.

The special roles played by the publishers of this work, who provided a platform for the work to get to the reading public are also duly acknowledged for their support.

\section{References}

Diako, C., Manful, J. T., Johnson, E. P. N. T., Dawson, S., Bediako-Amoa, B., \& Saalia, F. K. (2011). Physicochemical characterisation of four commercial Rice varieties in Ghana. Advance Journal of Food Science and Technology (3rd ed., Vol. 3, pp. 196-202). Department of Nutrition and Food Science, University of Ghana.

Fofana, M., Futakuchi, K., Manful, J. T., Yaou, I. B., Dossou, J., \& Bleoussi, R. T. M. (2011). Rice grain quality: A comparison of imported varieties, local varieties with new varieties adopted in Benin. Food Control, 22(12), 1821-1825. http://dx.doi.org/10.1016/j.foodcont.2011.04.016

International Rice Research Institute (IRRI). (1998). Registration of Jasmine 85. Crop Science, 38, 895-896.

ICC. (2004). Standard Methods of the International Association for Cereal Science and Technology. 6th Supplement. Methods No. 162 and No. 164, approved 1996. The Association: Vienna.

International Organisation for Standardisation. (2011). ISO/DIS 6647-2-Rice-Determination of amylose content. Part 2: Routine methods 10.

International Food Policy Research Institute. (2014). Substituting Rice Import in Ghana. Ghana Strategy Support Program (Policy No. 6).

Jennings, P. R., Coffmanm, W. R., \& Kauffmanm, H. E. (1979). Rice improvement. International Rice Research Institute Los Banos, Laguna, Philippines.

Li, J. Y., \& Yeh, A. L. (2001). Relationships between thermal, Rheological characteristics and swelling power for 
various starches. Journal of Food $\quad$ Engineering, $\quad 50, \quad$ 141-148. http://dx.doi.org/10.1016/S0260-8774(00)00236-3

Little, R. R., Hilder, G. B., \& Dawson, E. H. (1958). Differential effect of dilute alkali on 25 varieties of milled white rice. Cereal Chem., 35, 111-126.

Marco, M., Bollich, C., Webb, B., Jackson, B., McClung, A., Scott, J., \& Hung, H. (1997). Registration of 'Jasmine 85' Rice (Peer Review Journal, Last modified: August 20, 2013).

Singh, N., Singh, L., Kaur, L., Singh-Sodhi, N., Singh-Gill, B. (2003). Morphological thermal and rheological properties of starches from different botanical sources. Elsevier Science Food Chemistry, 81, $219-231$. http://dx.doi.org/10.1016/S0308-8146(02)00416-8

Tester, R. F., \& Morrison, W. R. (1990). Swelling and gelatinization of cereal starches. Cereal Chemistry, 67, 551-557.

World Bank. (2013). Growing Africa: Unlocking the potential of Agribusiness. Washington, DC: World Bank.

\section{Copyrights}

Copyright for this article is retained by the author(s), with first publication rights granted to the journal.

This is an open-access article distributed under the terms and conditions of the Creative Commons Attribution license (http://creativecommons.org/licenses/by/3.0/). 